\title{
Dacochordodes bacescui Capuse, 1966: Report of the first two isolations from humans
}

\author{
ZORAN P PIKULA MD, SERGEI E SPIRIDONOV PhD, EDNAR T DRLJEVIC MD
}

\begin{abstract}
ZP PIKULA, SE SPIRIDONOV, ET DRLJEVIC. Dacochordodes bacescui Capuse, 1966: Report of the first two isolations from humans. Can J Infect Dis 1996;7(2):144-146. This report describes two cases of isolation of Dacochordodes bacescui Capuse, 1966 from human intestinal infections. In the first case, two adult worms were identified in the vomitus of a man suffering from abdominal pain and nausea. In the second case, a worm was passed in the stool of a woman suffering from abdominal pain and pruritus. Human gastrointestinal infection with this parasite has not previously been reported.
\end{abstract}

Key Words: Dacochordodes bacescui, Human intestine, Nematomorpha

\section{Dacochordodes bacescui Capuse, 1966 : rapport des deux premiers cas isolés chez l'humain}

RÉSUMÉ : Ce rapport décrit deux cas où Dacochordodes bacescui Capuse, 1966 a été isolé lors d'infections intestinales chez l'humain. Dans le premier cas, deux vers adultes ont été identifiés dans les vomissements d'un homme souffrant de douleurs abdominales et de nausées, dans le deuxième, un vers a été évacué dans les selles d'une femme souffrant de douleurs abdominales et de prurit. L'infection gastro-intestinale due à ce parasite chez l'humain n'avait encore jamais été signalée.

$\mathrm{M}$ embers of the phylum Nematomorpha are usually called 'horsehair worms' because of their resemblance to long horse hair and because of an old belief that they arose from horses' hair that had fallen into water (1). Free-living adults dwell in environmental water sources, including streams, lakes and ponds. The four stages in the life cycle are (2): egg; preparasitic larva that hatches from the egg and enters a transport (paratenic) host, usually an invertebrate but it may also be a vertebrate, eg, fish; parasitic larva that develops to the adult form within a definitive host (usually insects); and free-living adult that emerges from the definitive host and lives and mates in fresh water.
There are three possible life cycles for nematomorphs (2). The first is the direct cycle, in which the egg hatches in water and the preparasitic larva is ingested by the definitive host. The second is the indirect free-living cycle, in which the preparasitic larva hatches from the egg, then encysts on leaves or water detritus until ultimately it is ingested by the definitive host. The third possible life cycle is the indirect paratenic type, in which, after hatching, the preparasitic larva is ingested by a transport host, burrows into the host's tissue, encysts and does not develop further unless the definitive host eats the transport host or parts of it. In all cycles the preparasitic larva enters the host by the mouth and encysts in the midgut tis-

Institute for Parasitology, Moscow, Russia, and Department for Infectious Diseases, Medical Center, Doboj, Bosnia and Herzegovina Correspondence: Dr Zoran P Pikula, 35 Thorncliffe Park Drive \#614, Toronto, Ontario M4H 1J3. Telephone 416-467-6392

Received for publication June 16, 1995. Accepted October 11, 1995 


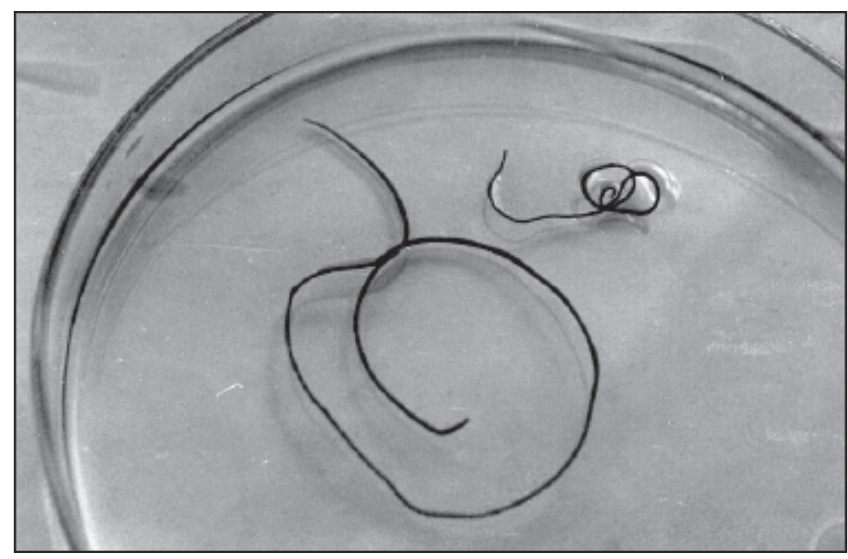

Figure 1) The female (left) and male (right) of Dacochordodes bacescui Capuse, 1966 vomited by case 1

sues. The adult form that matures in the host ultimately emerges from the host to live in fresh water.

The presence of these worms in the human body is considered to be accidental $(3,4)$. They may be introduced, however, by ingestion of the definitive host bearing an adolescent worm. The worms may then cause damage in their movement through tissues. Members of the families Gordidae and Chordodidae have been reported to cause infection in humans (3-8). Dacochordodes bacescui Capuse, 1966 (Chordodidae, Nematomorpha) was first described in 1966 by Capuse (9), who found a free-living male in Romania. The female Dacochordodes was first described by Spiridonov, Pikula and Drljevic in 1990 (10). To the authors' knowledge, this report presents the first two cases of isolation of this worm from humans.

\section{CASE PRESENTATIONS}

Case one: In October 1988 a 50-year-old man from a village in the Doboj district of the former Yugoslav republic of Bosnia and Herzegovina vomited what was described as "a dozen worms". Before this episode he had suffered mild abdominal pain, nausea and nervousness for several months. The worms were not collected for identification. The patient visited his physician and was treated with mebendazole tablets. Twenty days later, the patient vomited two more worms and a small, white particle. At that time, physical examination was normal. All requested laboratory tests (biochemical, hematological and microbiological) gave normal results except for a relative eosinophilia (10\%). After this episode the patient remained well and symptom-free for two years. The eosinophilia resolved in a few months.

The vomited worms were identified at the Helminthological Laboratory in Moscow as male and female Dacochordodes bacescui Capuse, 1966 (Chordodidae, Nematomorpha) (Figure 1). The male worm was dark brown, $98 \mathrm{~mm}$ long with a maximum diameter of $0.5 \mathrm{~mm}$ and weighed $28 \mathrm{mg}$. The anterior pole was colourless. The female was yellowish brown, $230 \mathrm{~mm}$ long with a maximum diameter of $0.8 \mathrm{~mm}$ and weighed $181 \mathrm{mg}$. A detailed morphological description of the worms has been previously published (10). The small, white

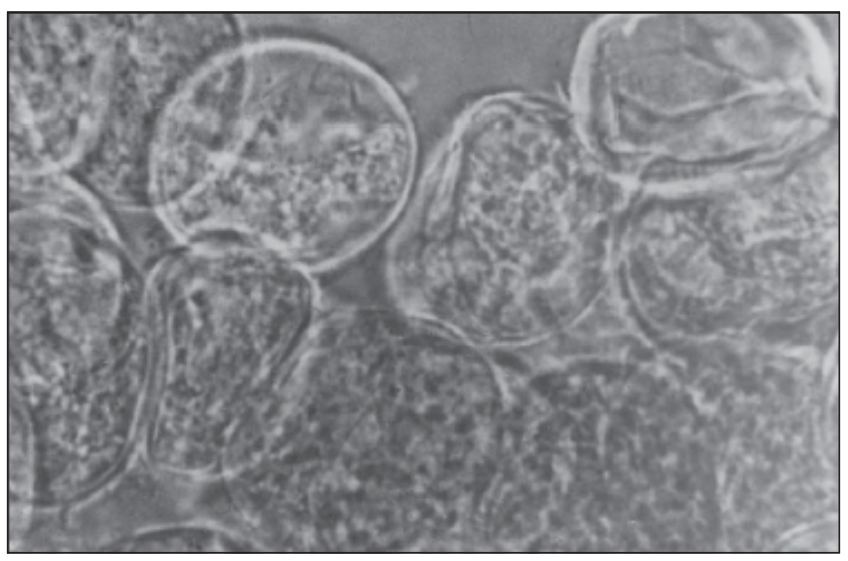

Figure 2) Eggs of Dacochordodes bacescui Capuse, 1966 in an early stage of development

particle was a thread filled with eggs in an early stage of development (Figure 2).

Case two: In September 1990 a 35-year-old woman from another village in the Doboj district found a worm in her stool. The worm was identified as a female Dacochordodes bacescui Capuse, 1966. It was dark brown, $161 \mathrm{~mm}$ long, with a maximum diameter of $1.0 \mathrm{~mm}$ and weighed $126 \mathrm{mg}$. The patient had suffered for several months from recurrent abdominal pain and pruritus and had diarrhea two days before passing the worm. Physical examination was unremarkable and radiographic investigation of her upper gastrointestinal tract and colon was normal. Routine biochemical and hematological tests, and bacteriological and parasitological analysis of three stools were normal. She was treated with diet alone and recovered within a few days.

\section{DISCUSSION}

Infection by 'horsehair worms' in humans is rare. Watson (4) lists 27 cases in Europe, Africa, and North and South America. The nematomorphs were usually identified in intestinal sites, but worms have also been reported in the urethra (8), vagina (3), ear (3) and eye orbit (3). Ali-Khan and AliKhan (5) reported Paragordius varius Leidy,1898 passed in the stool of a woman from Canada. Herter and Nese (6) described four cases of intestinal infection with Gordius robostus, and Subota (7) reported one case in Yugoslavia with a Gordius species worm passed in the stool of a woman suffering diarrhea and abdominal pain.

We presume that the worms from both patients reported here were ingested after drinking unfiltered water with insects present. Both these patients obtained drinking water from local water supplies. An alternate possibility is that food contaminated with insects (the definitive host) was ingested. In this case, one would postulate that the worm, in the larval stage in the definitive host, continued its development to the adult form in the intestine of the patient. Eggs may have been present in vomit due to ingestion with water or from the worms' reproducing in the intestine. The definitive host for this parasite in the Doboj district remains unknown, and investigations are needed to describe its ecology further. 
ACKNOWLEDGEMENTS: We thank Catherine Smitka and Colette Fijalkowski for critical reading of the manuscript.

\section{REFERENCES}

1. Poinar GO, Doelman JJ. A reexamination of Neochordodes occidentalis (Mont) comb N (Chordodidae: Gordioidea): Larval penetration and defense reaction in Culex pipiens l. J Parasitol 1974;60:327-35.

2. Poinar GO Jr. Nematomorpha. In: Trops JH ,Covich AP, eds. Ecology and Classification of North American Freshwater Invertebrates. New York: Academic Press, 1991:249-83.

3. Faust EC, Russel PF, Jung RC. Nematomorpha. Gordiacea. "Hairworms or Hairsnakes". In: Faust EC, Russel PF, Jung RC, eds. Craig and Faust's Clinical Parasitology. Philadelphia: Lea \& Febiger, 1974:405-6.
4. Watson JM. Nematomorpha and mermithoidea. In: Watson JM, ed. Medical Helminthology. London: Bailliere Tindal and Cox, 1960:445-9.

5. Ali-Khan FE, Ali-Khan Z. Paragordius varius Leidy infection in man: a case report from Quebec. J Parasitol 1977;63:174-6.

6. Herter CD, Nese RE. Pseudoparasitism with Gordius robostus. Am Fam Physician 1989;39:139-42.

7. Subota G. Endoparazitizam Nematodes Gordius i Mulleri. Medicinski Zapisi 1966;19:189-91.

8. Burger R. Paragordius esavianus passed per urethra. J Urol 1972;108:469.

9. Capuse I. Sur le Dacochordodes bacescui Capuse Ord. (Chordodida, Fam Chordodidae). Trav Mus Hist Natur "Grigore Antipa" 1966;6:17-23.

10. Spiridonov SE, Pikula ZP, Drljevic ET. Redescription of Dacochordodes bacescui Capuse, 1966 (Nematomorpha, Chordodidae). Helminthologia 1992;29:193-6. 


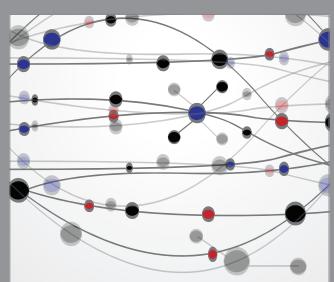

The Scientific World Journal
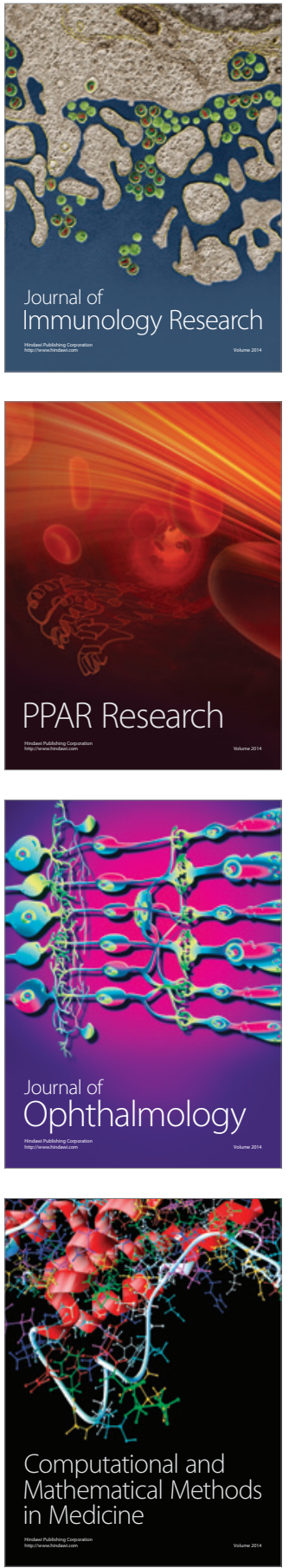

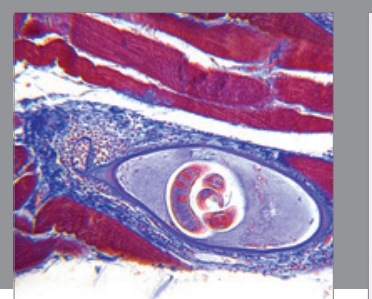

Gastroenterology Research and Practice

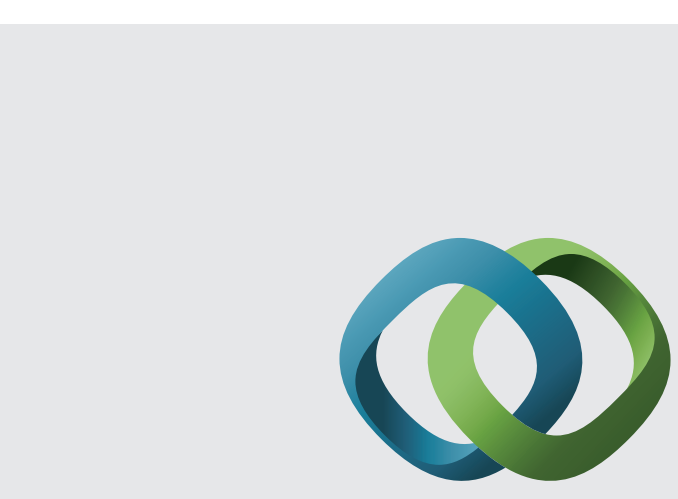

\section{Hindawi}

Submit your manuscripts at

http://www.hindawi.com
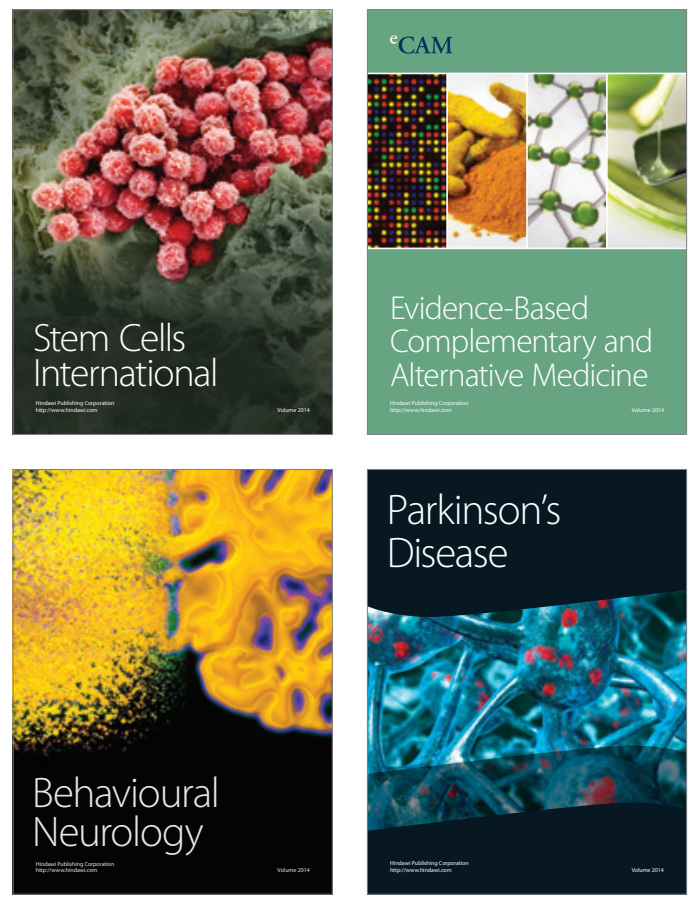
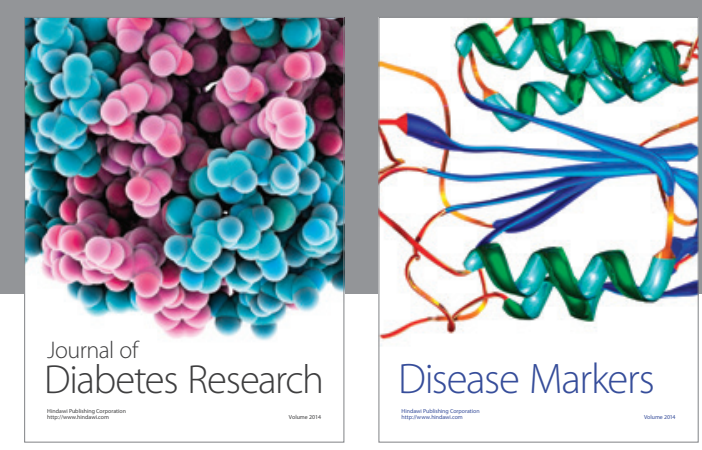

Disease Markers
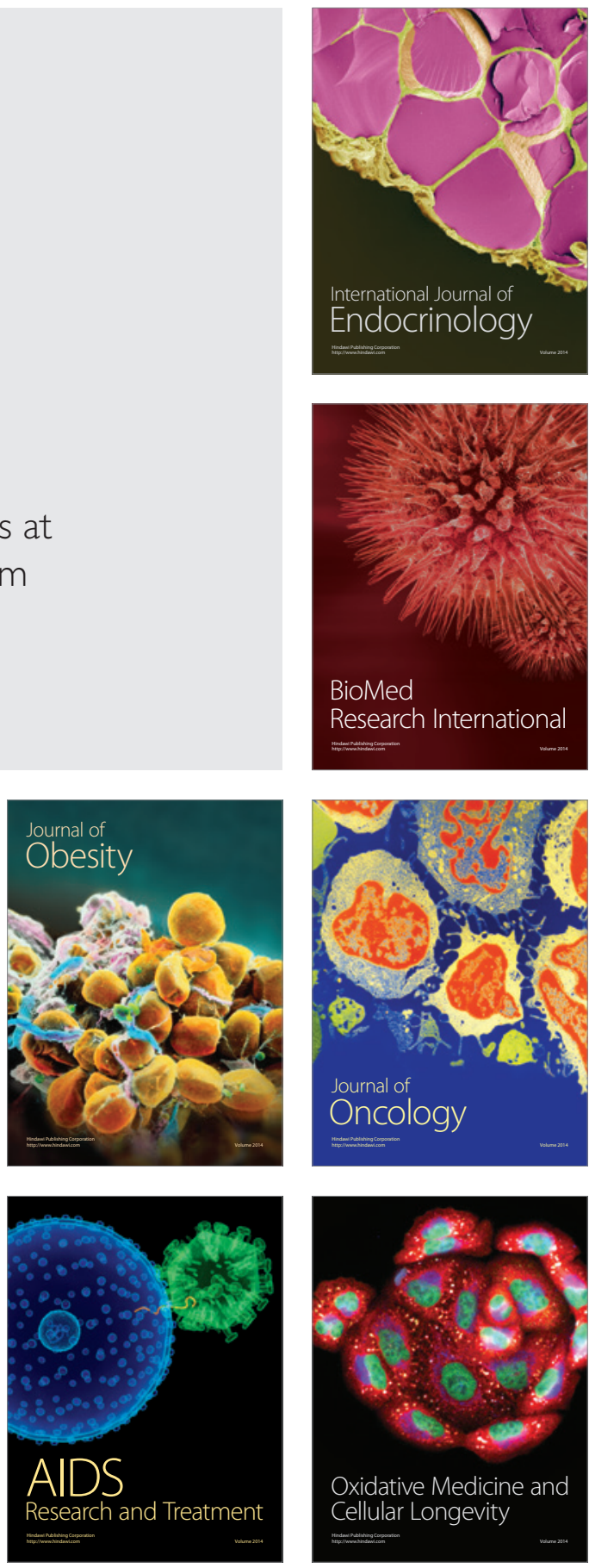